\title{
Student-Teachers' Practicum as the Scenario to Build Cumulative Learning through Semantic Waving Instructional Models
}

\author{
Eliana Garzón Duarte ${ }^{1,2}$ \\ ${ }^{1}$ University of Szeged, Szeged, Hungary \\ ${ }^{2}$ Universidad Distrital Francisco José de Caldas, Bogotá, DC, Colombia \\ Email:eliaga@yahoo.com,egarzond@udistrital.edu.co
}

How to cite this paper: Garzón Duarte, E. (2020). Student-Teachers' Practicum as the Scenario to Build Cumulative Learning through Semantic Waving Instructional Models. Open Journal of Social Sciences, 8 , 77-88.

https://doi.org/10.4236/jss.2020.82007

Received: January 5, 2020

Accepted: February 17, 2020

Published: February 20, 2020

Copyright $\odot 2020$ by author(s) and Scientific Research Publishing Inc. This work is licensed under the Creative Commons Attribution International License (CC BY 4.0).

http://creativecommons.org/licenses/by/4.0/

\begin{abstract}
The purpose of this conceptual article is to provide insights on how student-teachers of any Bachelor of Education program might become main actors in the space of the practicum when they help their pupils build up abstract understanding from concrete knowledge. This goal can be achieved through, firstly, an explicit teaching of semantic waving and knowledge construction as part of a theory-based teacher education course, and secondly, the implementation of lesson plans based on gravity waving instructional models during their practicum. The theories that frame this proposal and are presented in this article are semantic gravity and semantic density, stated by Karl Maton; Basil Bernstein's theory of "discourses" and "knowledge structures"; and, the conceptualization of reflective teaching. This article illustrates an example of the essential stages an instructional model based on semantic gravity might include. For this example, a model of a class of English as a Foreign Language (EFL) Teaching Methodology is taken into account.
\end{abstract}

\section{Keywords}

Semantic Gravity, Knowledge Structures, Cumulative Learning, Reflective Teaching, Teacher Research, Instructional Model, Practicum

\section{Introduction}

It is common to find in different curricula at school or university level that the subjects or seminars comprise a series of objectives to be achieved by the students, without taking into account previous encountered knowledge or without making connections with other disciplines. According to Maton (2010), segmentalism is a tendency to work in an isolated way in the classroom by engaging students in 
learning processes in which they accumulate different contents as they advance in the curriculum of the school but failing in the integration and progressive construction of knowledge. This phenomenon occurs precisely because of the type of pedagogical practices teachers perform in their classrooms, as well as the curricula design of the schools, where cumulative building of knowledge is not present. What segmentalism causes in education is that students cannot apply their understandings to other studies or new contexts of everyday life.

One of the main goals of education must be to enable cumulative learning for students to develop their capacity to integrate their past experiences to new contexts, giving them the opportunity to be prepared for lifelong learning. Instructional models based on the explicit work of semantic gravity and semantic density might become a pedagogical strategy to avoid this issue of segmental learning. A significant point of departure to build this model is in teacher education programs, where student-teachers have to read, learn and interpret different teaching and learning theories, approaches, and methods and then implement them in the design and planning of lessons when doing their practicum. Thus, there will be a cascade effect where these student-teachers can continue with this type of pedagogical practice based on models of semantic gravity and density in their professional future as in-service teachers.

This article presents a section of the theoretical foundations that lead this proposal of semantic waving instructional models; then, a general example of how it would work in the practicum of EFL student-teachers is illustrated; and finally, the pedagogical implications and conclusions are provided. What this proposal intends to highlight is that instructional models based on semantic gravity can be designed and applied in any discipline, thus if student-teachers of different areas of knowledge are aware of the implications and stages of this strategy, the work they do with their pupils in their practicum will have more integrated results and in future, as in-service teachers, they will continue to enhance the cumulative learning construction in their classrooms.

\section{Theoretical Foundations}

In this section, firstly, the understanding of knowledge is explained as well as the importance of how this concept should be explicitly addressed in educational research in order to recognize it as the basis of education, which is rightly a social field of practice. Secondly, the examination of knowledge structures is described to comprehend how they are linked to semantic gravity through the creation of gravity waves in order to build and assemble knowledge across contexts and time. This argument is also supported with the model of discourses and knowledge structures stated by Bernstein (1999) and the three fields of practice of pedagogic discourse also proposed by him in 1990. Furthermore, the reflective model of Wallace (1991) will provide insights about the work teachers should do in the classroom to connect the theories with the reality as part of a never-ending process. This reflective teaching process involves research as well in 
the sense that the analytical and structured processes of observation, analysis, and evaluation are continuously present in the pedagogical practice. Therefore, the ability of passing through abstract knowledge to situated knowledge is what makes part of the semantic waves model (Maton, 2009, 2013).

\subsection{Towards the Understanding of Knowledge and Knowledge Structures}

One of the relevant issues, argued by Maton (2013) that generates segmented learning in education is precisely the understanding of educational knowledge, which reflects the knowledge blindness of educational research. It is the teaching and learning of knowledge what makes education a distinctive field. Knowledge is often confined (Maton, 2014a) and it is frequently seen under a social constructivist perspective that only reflects social characteristics to be analyzed, rather than concentrating on the forms of knowledge. Knowledge, for example, can vary internally based on if it is abstract or concrete, context-dependent or independent, based on personal experience or on specialist languages. The result of this blindness is that knowledge is left under-researched. Maton (2014a) also states that in educational practices, educators tend to see knowledge building as a focus on knower dispositions or experiential elements.

Therefore, it is completely necessary for educators to move beyond this relativist approach and be aware of knowledge as something real and structured. Maton (2009) argues that there are knowledge structures that integrate a large number of "empirical phenomena with the smallest number of axioms" (p. 45). The transitions between these axioms or more abstract knowledge structures and those structures that are more empirically-oriented is known as semantic gravity; in other words, the proximity or dependence of the context through concrete ideas or situated cases. Maton (2013) states that "semantic gravity (SG) refers to the degree to which meaning relates to its context" (p. 11).

The reciprocity between the structures of knowledge creates gravity waves, which is a process of knowledge building due to the fact that it facilitates the intensification of knowledge across contexts and through time: "It therefore represents cumulative learning” (Maton, 2009: p. 45). Likewise, Maton (2013) explains that the distance to the context produces abstraction and meanings that are condensed, which he denominates semantic density. This density can be expressed in symbols, specialized language, and expressions. Therefore, discourse might wave between semantic gravity and density, and thus passing from abstract ideas to concrete cases.

Semantic gravity can be weaker or stronger according to the relation between the meaning and the context. "The stronger the semantic gravity (SG+), the more meaning is dependent on its context; the weaker the semantic gravity (SG-), the less dependent meaning is on its context" (Maton, 2013: p. 11). Processes of strengthening semantic gravity can be also described as moving from abstract or generalized ideas towards specific or situated cases, and 
processes of weakening semantic gravity as moving from concrete cases towards generalizations and abstractions. In other words, the purpose of the semantic gravity is to analyze how much reliance on specific contexts the meanings have to make sense.

Consequently, semantic gravity fluctuates on this sequence, changing from stronger to weaker dependence and from weaker to stronger as well forming waves that can be represented graphically. When exploring and analyzing these semantic waves in the pedagogical practices and tracing them through time, a semantic profiling (Maton, 2014b) can be illustrated as the example in Figure 1. This representation also visualizes the development of the curriculum, a textbook, or any other pedagogical material used in the classroom. The strengths of semantic gravity and density between highest and lowest determine the semantic ranges. Figure 1 exemplifies three different semantic profiles, where the $y$ axis scales the strengths and the $x$ axis the time. The semantic line A is flat and high, the semantic line $B$ is also flat, but low; and the semantic wave $C$ reaches the highest semantic range. The semantic flatlines, as in the case of lines A and B, are formed when the meanings prevail either abstract or situated.

This conceptualization and appropriateness of semantic gravity may start to solve issues in education as the one related to segmental learning. Knowledge structures, curriculum structures, and teaching and learning practices can be described as points on a continuum.

\subsection{Bernstein and His Model of Discourses}

Bernstein (1999) distinguishes between two types of discourse: Horizontal and vertical. Both of them founded on the understanding of knowledge: "Vertical discourse takes the form of a coherent, systemic, well organized discourse or it takes the form of a series of specialized languages with specific modes and criteria for the production of texts" (p. 159), and horizontal discourse, instead, "takes the form of everyday or common-sense knowledge and entails a set of local, segmentally organized, and context dependent set of strategies" (p. 159). In other words, meaning is dependent on its context, so knowledge acquired in one context does not have necessarily meaning in other contexts. Therefore, when

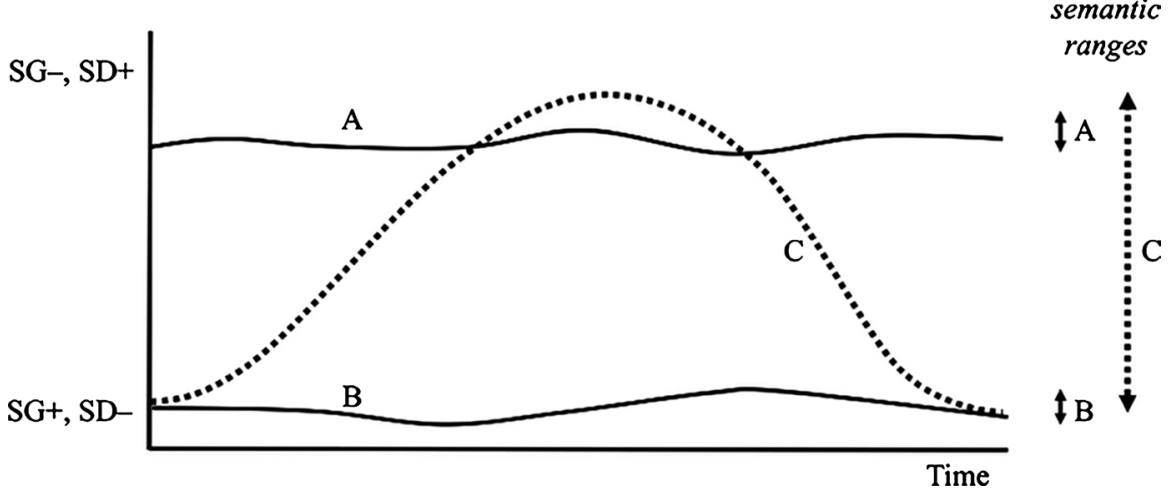

Figure 1. Diagram of three semantic profiles (Maton, 2014b: p. 6). 
these two types of discourse are analyzed, an inseparable link with the conceptualization of semantic gravity can be understood.

Consequently, in vertical discourse, hierarchical educational knowledge structures exhibit weaker semantic gravity than horizontal educational knowledge structures, and cumulative learning represents weaker semantic gravity than segmented learning. Semantic gravity can be applied to knowledge structures, curriculum structures, and teaching and learning practices, so it enables a more integrated and connected view and understanding of education. Therefore, it is important to recognize that the space given in the practicum of student-teachers, should be reconsidered as a bridge to connect the abstract knowledge of the teaching theories and the real practices in the classrooms. This could be done by the student-teachers when reflecting, analyzing, and evaluating their groups of learners and practices; and then, planning and applying a semantic gravity pedagogical model to immerse learners into an atmosphere of cumulative learning construction. Brooke (2017) claims that students with high-order thinking skills evidence an ability to move from ranges of abstract knowledge or context-independent knowledge to situated or context-dependent knowledge and the other way around, which creates the process of gravity waving. Szenes, Tilakaratna, and Maton (2015) state that these movements or transitions between ranges of knowledge is high-achieving work, so the awareness of constructing this ability should be enhanced in student-teachers. Effective critical thinking and cumulative learning in any field of study is built through the interaction between different knowledge structures.

There is another theory of discourse proposed by Bernstein (1990) and it is the pedagogic one. Here, Bernstein makes emphasis on how discourse works in society and the role it has in maintaining social order. Therefore, he focuses on discourse related to education and explains that there are three fields of practice in order to analyze the grammar of pedagogic discourse (Bernstein, 2000): 1) Production, where new knowledge is constructed and positioned; 2) reproduction, where the pedagogic practice occurs; and 3) recontextualizing, where discourses from the field of production are selected, appropriated and transformed to become pedagogic discourse available to be taught and learnt in the field of reproduction. In Bernstein's (1990) words, pedagogic discourse is a principle for appropriating other discourses from the field of production and making them be pedagogized. So, it can be said that the three fields of practice are the contexts that shape pedagogic discourse.

\subsection{Reflective Teaching}

When understanding and applying semantic gravity in teaching practices, educators can definitely move from segmentalism to cumulative learning. First, practices of production, recontextualization, and reproduction can each be understood as realizations of different degrees of semantic gravity, enabling changes traces in the curriculum between fields. Second, tracing objectives and 
profiles over time is crucial for understanding enabling conditions for cumulative knowledge-building. Last, conceptualizing knowledge practices in terms of semantic gravity evidences that one condition for cumulative-knowledge building and learning may be the capacity to master semantic gravity. Thus, knowledge can be firstly decontextualized; then, transferred; and finally, recontextualized into new contexts.

Furthermore, it is necessary to bring the connections existing between this model of semantic gravity and its awareness and application in the spaces of practicum with the model of reflective teaching proposed by Wallace (1991) and Richards and Lockhart (1995). Reflective teaching is an approach in "which teachers and student-teachers collect data about teaching, examine their attitudes, beliefs, assumptions and teaching practices, and use the information obtained as a basis for critical reflection about teaching" (Richards \& Lockhart, 1995: p. 1). This critical reflection implies to inquire about how and why things are the way they are, the current possibilities of work based on assessment results, and the flaws of doing things one way or another. These reflective inquiries lead the student-teachers into the process of grounding theories or abstract knowledge in situated contexts.

Professional development is a never-ending process which is founded on reflection connected to pedagogical experiences. Thus, the reflective model is a "structured professional development model that acknowledges teaching as a profession in the sense that to become a teacher, we have to master some knowledge that other professions do not have" (Posada-Ortiz \& Garzón-Duarte, 2014: p. 125). The reflective model proposed by Wallace (1991) describes three stages for its application: 1) Pre-training, 2) Professional development, and 3) Professional competence. The pre-training stage emphasizes the reality that student-teachers react to any situation in the classroom dependent on the mental constructs and beliefs they already have about that particular event and their feelings they experience at that specific moment. Therefore, this stage has to do with all the personal, social, academic and cultural background the student-teachers bring to the classroom.

The professional development stage draws attention to two types of knowledge: the received and the experiential. The received knowledge has the same structure as the abstract knowledge already explained. It refers to the theories, methods, approaches student-teachers learn in their curriculum at the university. The experiential knowledge has to do with the decisions made by the student-teachers in the classroom and the skills they use based on their feelings. It is related to the situated, concrete or context-dependent knowledge. Consequently, the semantic waves also emerge in this learning and teaching process of the student-teachers when they transit from one type of knowledge to the other one. That is why I want to highlight the importance of working this semantic waving model explicitly in the curriculum of any teacher education program, so student-teachers become aware of this process of learning construction and un- 
derstand the roots and purpose of learning to apply it as well in the design of their syllabi when doing their practicum and later on, in their pedagogical practices as in-service teachers. Professional competence stage is then the horizon of teachers. It is a continuous process "which is never finally attained" (Wallace, 1991: p. 58). The force of the expertise in which a special skill or knowledge is acquired by training, studying, or practicing is stronger in this stage.

\section{Proposal of Instructional Model}

This is a proposal of an instructional model based on semantic waves for student-teachers to take into consideration when doing the practicum. It is also based on a model proposed by Brooke (2017) to guide students to the research process. When understanding and applying semantic gravity in teaching practices, educators can definitely move from segmentalism to cumulative learning. This instructional model for a course of methodology in a B.Ed program goes along four stages as follows:

\subsection{First stage: Explicit Theories and Approaches}

In this first stage, student-teachers read and discuss theories, approaches and methods to teach English as a Foreign Language (EFL), including the semantic waving model to construct cumulative building. They prepare oral presentations, write summaries, and work on group discussions. They read examples of pedagogical practices and identify the type of teaching method they correspond to. So, in this stage, it can be seen that the semantic gravity is weaker (SG-) because the meaning of the teaching theories, methods, and approaches is not dependent on the context, but more on abstract terms and generalizations.

\subsection{Second Stage: Explicit Cases Implementing Specific Teaching Methods}

Here, tutors give a list of EFL themes to be worked in the school and encourage the student-teachers to use a specific teaching method to apply the theory previously studied. The students can also make their own selection of the teaching method to be used and prepare concrete examples of the semantic gravity model. For this, they have to read articles and samples of instructional models. Then, discuss their examples with their classmates to complement them and improve them, if it is the case, with the guidance of the tutor. The meaning of the instruction in this stage is mixed; it goes from dependent on the context (SG+) to independent of the context (SG-), creating semantic waves.

\subsection{Third Stage: Observation of Schools}

After having completed the two first stages, student-teachers do field work of observation in the school where they are going to do the practicum. In this school, they do a systematic observation of the general environment of the school and the class where they are going to perform as pre-service teachers. 
They also read the school policies, regulations, and the EFL curricula. They write their insights of the observations and describe the pedagogical practices they observed in the classroom and identify the existent or non-existent connections between the curricula and the practices they observed. This stage is totally dependent on context, so the semantic gravity is stronger (SG+).

\subsection{Fourth Stage: Using Theoretical Framework to Design a Pedagogical Implementation in the Practicum}

After doing the observation process of the school, student-teachers prepare an instructional model based on semantic waving to be implemented in their group of practicum at the school. For this stage, they have to include all the themes that must be covered in the EFL class and relate themes from other disciplines of the school to be used as part of the reading process and pedagogical activities of the lessons. In this stage, the sessions with the tutor are very important to assess the whole process of implementation of the model. The meaning of instruction in this stage is totally contextualized (SG+). However, the importance of this stage is that student-teachers have the opportunity of creating materials, activities and methods considering how their pupils learn and helping them achieve their academic goals as well as constructing cumulative learning. Therefore, in this stage, it is hoped that the student-teachers understand the effectiveness of gravity waves and the shifts from context-dependent and context-independent knowledge structures to engage their pupils in a critical learning process.

In EFL classes, one clear example of the application of the semantic waves is precisely the teaching of grammar. Teachers can design effective lessons that promote shifts from theoretical abstract to contextualized meanings or the other way around to develop higher order thinking skills in students to make them see language as the vehicle to read the whole world from the different perspectives and disciplines. Grammar is the structured system of language and all the world is the context to understand grammar. Therefore, innumerable activities and creative lesson plans to teach not only EFL, but also language are possible with the use of semantic gravity waving.

\section{Pedagogical Implications of This Proposal}

The path of mastering semantic gravity, in the case of student-teachers, becomes a step-by-step process of internalizing abstract theories of teaching and contextualization. This means that the explicit work with semantic gravity could help student-teachers grasp the difference between theories of teaching and learning, context, and the interrelationship between context and theories, which is essential for the appropriation of the concept of gravity waving. It is necessary to clarify that the explicit instruction of semantic gravity should be built through a suitable instructional model.

It is worth noting here the role of assessment during the implementation of the instructional model. In every stage of the instructional model, the steps of 
the semantic waving model are explicit explained to the student-teachers and they assess the process by reflecting upon the type of activities they perform in class through specific questions. For example, if the teacher was helping them understand abstractions through the use of contextualized examples or if the activities prepared by the teacher were more addressed to reframe their understanding in more abstract knowledge. This assessment is one of the most important processes inside the proposal of this instructional model because it permits student-teachers understand the shifts from context-dependent to context-independent knowledge structures. They can also verify how teachers can take advantage of these semantic waves in the lesson planning to engage learners in the construction of cumulative and critical learning.

According to Bernstein (2000), practices of production, recontextualization, and reproduction can each be understood as realizations of different degrees of semantic gravity, enabling changes traces in the curriculum between fields. This has to be taken into account when designing instructional models. Besides, tracing objectives and profiles over time is crucial for understanding enabling conditions for cumulative knowledge-building, so this must be included in the explicit teaching of the method to illustrate the student-teachers the shifts that occur in the pedagogical practice. Conceptualizing knowledge practices in terms of semantic gravity evidences that one condition for cumulative-knowledge building and learning may be the capacity to master semantic gravity. Thus, knowledge can be firstly decontextualized; then, transferred; and finally, recontextualized into new contexts.

Building powerful knowledge through the significance of semantic waves (Marton, 2014b) is linked to the empowerment of future teachers to make informed decisions in the classroom and design more resources that imply construction of cumulative learning and specialized knowledge. The effective results of these implementations are directly connected to the importance of research in the classroom. Teacher research makes teachers resist the current trends of segmental curricula imposed, most of the times, in a top-down manner by administrative staff and policy makers (Kincheloe as cited in Lankshear \& Knobel, 2004: p. 5). Thus, the research component in a program of teacher-education is a main tenet to find ways of observing systematically and analyzing the situations and experiences of the classroom to engage the student-teachers in the construction of pedagogical proposals to be implemented during their practicum, and in their future teaching contexts as well.

Student-teachers with the guide of their practicum tutors might develop interesting pedagogical interventions or instructional models for their classes. All of this based on a permanent critical reflection upon the experiences lived in the classroom. Therefore, student-teachers are able to assess if their pedagogical practices are collaborating to engage their learners in the building of cumulative learning, which implies critical thinking or if their practices still remain in the ground of segmentalism. This work is a path of empowering student-teachers in 
decision making processes about teaching and learning. They should feel confident and responsible of the process they are addressing in the classroom.

Cumulative learning requires, therefore, mastering of semantic gravity. Educators can overcome the polarized thinking that learning is only given in terms of static flatlines if they understand the concept of semantic gravity, which describes a continuum of forces that can be interpreted through time as tracking a profile. This conceptualization makes educators go beyond comparing static flatlines to drawing a trajectory of change. Consequently, a potential change to be implemented in teaching practices to achieve higher-order thinking objectives in students is to extend the range of movements between stronger and weaker semantic gravity. These movements in semantic gravity add a state for the decontextualization and recontextualization of knowledge and hence the opportunity of cumulative knowledge-building and learning.

When analyzing the proposal of instructional design presented in this article, it can be found that observation, critical reflection, and pedagogical interventions go hand in hand with research design. Moreover, it is evident that the gravity waving model is linked directly to this critical reflection process and the stages to design a research study in the school or in a specific classroom. This explicit work on gravity waving through instructional models make student-teachers be able to observe systematically, read and think critically to create enriching pedagogical proposals that allow learners to construct a real lifelong learning. If the student-teachers understand how gravity waving works, they can connect thinking, pedagogical practices, and research design significantly.

It is important to find the point of balance to include semantic waving in every teaching practice. When designing exams, for example, educators also have to set questions with these transitions between weaker and stronger semantic gravity. It is important for the development of critical skills in their students. The design of these exams will require more effort and time, but the students will know and understand that knowledge is structured and that everything is related when learning.

\section{Conclusion}

The purpose of this article has been to present the importance of mastering semantic gravity and density in teaching practices to build cumulative learning, and thus avoiding the issue of segmentalism in education. Instructional models based on explicit gravity waving can facilitate the awareness of building knowledge to be applied not only in specific situated contexts, but also in new and different contexts, making students see all the relations between the disciplines to understand realities. Explicit gravity waving teaching in seminars of teaching methods in the programs of teacher education might become starting points for its implementation. This model is essential to develop higher-order thinking skills in future teachers, who are the ones in charge of replicating these learning outcomes in their educational contexts; first, when doing their practicum, and 
later on, in their workplaces. Moreover, future teachers and educators should be more conscious of intentionally moving between the higher and lower semantic density, and weaker and stronger semantic gravity.

This proposal of mastering semantic gravity in teaching practices is a gradual and longitudinal process that needs the collaboration between educators, student-teachers, researchers, and curriculum designers. However, the results of these practices will assure students to build a lifelong learning. Changing classroom pedagogies and practices in ways such as the understanding, appropriateness, and application of semantic gravity may enable more students to build knowledge and learning to succeed and see the world like an interconnected whole.

The example of instructional model presented in this article is organized within four stages which can be adapted to new proposals and any field of teacher education programs. Conceptualizing discourses, knowledge structures, curriculum structures, and forms of learning as realizations of strengths of semantic gravity offers a relevant step towards a more integrated account of education. When these concepts are used to explore educational practices, curriculum designers and educators are able to identify ways in which the forms taken by knowledge practices may help facilitate or constrain cumulative learning. These concepts should be worked with explicit guidance in the different educational levels. Most of the times, the goal for students to learn higher-order principles of knowledge to be applied to new contexts is written explicitly in the syllabus of different fields and curricula of the educational system, but teaching practices evidence the opposite. Students' understandings remain rooted in their specific contexts, evidencing a strong semantic gravity.

If the mastery of semantic gravity starts by being explicitly taught and worked in different levels of education, students will be able to understand gravity waving and connect their thinking and learning to new contexts of life. Therefore, programs of teacher education have to reconsider the inclusion of this mastery in their curriculum. Gravity waving should become a pedagogical principle to organize, design, and develop teaching practices, even more so when working with student-teachers. These future teachers need to find awareness of gravity waving in teaching and learning practices, so they can extrapolate it in their practicum. This means that student-teachers will design instructional models that can be analyzed with the help of the practicum advisor, and thus build a strong basis of higher-order principles of knowledge in their students and in themselves as future teachers. Moreover, the practicum advisors will raise awareness in the importance of gravity waving when guiding their student-teachers and observing their performance in the classroom.

\section{Conflicts of Interest}

The author declares no conflicts of interest regarding the publication of this paper. 


\section{References}

Bernstein, B. (1990). Class, Codes and Control, Volume IV: The Structuring of Pedagogic Discourse. London: Routledge. https://doi.org/10.4324/9780203011263

Bernstein, B. (1999). Vertical and Horizontal Discourse: An Essay. British Journal of Sociology of Education, 20, 157-173. https://doi.org/10.1080/01425699995380

Bernstein, B. (2000). Pedagogy, Symbolic Control and Identity: Theory, Research, Critique. Revised Edition. Oxford: Rowman and Littlefield.

Brooke, M. (2017). Using "Semantic Waves" to Guide Students through the Research Process: From Adopting a Stance to Sound Cohesive Academic Writing. Asian Journal of the Scholarship of Teaching and Learning, 7, 37-66.

Lankshear, C., \& Knobel, M. (2004). A Handbook for Teacher Research: From Design to Implementation. Oxford, UK: Oxford University Press.

Maton, K. (2009). Cumulative and Segmented Learning: Exploring the Role of Curriculum Structures in Knowledge-Building. British Journal of Sociology of Education, 30, 43-57. https://doi.org/10.1080/01425690802514342

Maton, K. (2010). Segmentalism: The Problem of Building Knowledge and Creating Knowers. In D. Frandji, \& P. Vitale, (Eds). Knowledge, Pedagogy and Society. International Perspectives on Basil Bernstein's Sociology of Education. London: Routledge.

Maton, K. (2013). Making Semantic Waves: A Key to Cumulative Knowledge-Building. Linguistics and Education, 24, 8-22. https://doi.org/10.1016/j.linged.2012.11.005

Maton, K. (2014a). A Tall Order? Legitimation Code Theory for Academic Language and Learning. Journal of Academic Language \& Learning, 8, 34-48.

Maton, K. (2014b). Building Powerful Knowledge: The Significance of Semantic Waves. In E. Rata, \& B. Barrett, (Eds). The Future of Knowledge and the Curriculum (pp. 1-15). London: Palgrave Macmillan. https://doi.org/10.1057/9781137429261_12

Posada-Ortiz, J., \& Garzón-Duarte, E. (2014). Bridging the Gap between Theory and Practice in a B.A. Program in EFL. HOW Journal, 21, 122-137. https://doi.org/10.19183/how.21.1.19

Richards, J. C., \& Lockhart, C. (1995). Reflective Teaching in Second Language Classrooms. Cambridge, UK: Cambridge University Press. https://doi.org/10. 1017/CB09780511667169

Szenes, E., Tilakaratna, N., \& Maton, K. (2015). The Knowledge Practices of Critical Thinking. In M. Davies, \& R. Barnett, (Eds), The Palgrave Handbook of Critical Thinking in Higher Education. London: Palgrave Macmillan. https://doi.org/10.1057/9781137378057 34

Wallace, M. J. (1991). Training Foreign Language Teachers: A Reflective Approach. Edinburgh, UK: Cambridge University Press. 